\title{
Environmental $\mathrm{pH}$ modulates biofilm formation and matrix composition in Candida albicans and Candida glabrata
}

\author{
Bruna Gonçalves (D), Liliana Fernandes, Mariana Henriques (D) and Sónia Silva \\ LIBRO - Biofilm Research Laboratory Rosário Oliveira, CEB - Centre of Biological Engineering, University of Minho, Braga, Portugal
}

ABSTRACT

Candida species are fungal opportunistic pathogens capable of colonizing and infecting various human anatomical sites, where they have to adapt to distinct niche-specific $\mathrm{pH}$ conditions. The aim of this study was to analyse the features of Candida albicans and Candida glabrata biofilms developed under neutral and vaginal acidic ( $\mathrm{pH} 4)$ conditions. C. albicans produced thicker and more filamentous biofilms under neutral than under acidic conditions. On the other hand, the formation of biofilms by C. glabrata was potentiated by the acidic conditions suggesting the high adaptability of this species to the vaginal environment. In general, both species developed biofilms containing higher amounts of matrix components (protein and carbohydrate) under neutral than acidic conditions, although the opposite result was found for one C. glabrata strain. Overall, this study contributes to a better understanding of the modulation of $C$. albicans and $C$. glabrata virulence by specific $\mathrm{pH}$ conditions.
ARTICLE HISTORY

Received 14 May 2020

Accepted 2 July 2020

\section{KEYWORDS}

Candida species; lactic acid; virulence factors; vulvovaginal candidiasis

\section{Introduction}

Candida species which are the most common yeasts found in the normal human microbiome are also capable of causing morbidity and mortality (Alberto Cortés and Fernanda Corrales 2019). Candidiasis is associated with a wide variety of clinical manifestations, ranging from mucosal infections with mild severity to life-threatening bloodstream infections (Pappas et al. 2016). Candida albicans is the leading cause of candidiasis but a trend to non-Candida albicans Candida species (NCAC), especially Candida glabrata, has been suggested by some epidemiologic surveys (Gonçalves et al. 2016; Alberto Cortés and Fernanda Corrales 2019). C. glabrata has high clinical relevance owing to its low susceptibility to some classes of antifungals and its ability to develop resistance following exposure to antifungal agents (Bennett et al. 2004; Nagashima et al. 2016).

The pathogenicity of Candida species is mediated by several virulence factors, including the ability to form biofilms on mucosal surfaces and indwelling medical devices (Harriott et al. 2010; Bouza et al. 2014). C. albicans forms thick, spatially organised complex biofilms comprised of a multilayered and intertwined network of blastospores, pseudohyphae and hyphae, partially embedded in an extracellular matrix (Seneviratne et al. 2009). Importantly, although readily formed in planktonic cultures, in the presence of specific nutritional cues, hyphae are a characteristic feature of C. albicans biofilms and required for their proper formation (Nobile et al. 2012; Gulati and Nobile 2016). The hyphae contribute to the architectural stability of biofilms by forming a scaffold that provides a robust support for the extracellular matrix as well as the blastopores, pseudohyphae and other hyphae (Seneviratne et al. 2009; Gulati and Nobile 2016). Nevertheless, studies on C. glabrata, which does not naturally form true hyphae, suggest that hyphal morphology is not a prerequisite for biofilm formation. Indeed, C. glabrata develops thin and patchy, rather compact biofilms, exclusively of blastospores embedded within an extracellular matrix (Seneviratne et al. 2009). The association of microorganisms into biofilms contributes to their survival under hostile environmental conditions (Donlan and Costerton 2002).

One of the main challenges faced by Candida species during commensal and pathogenic lifestyles is the wide range of environmental $\mathrm{pH}$ in host niches, from acidic (vagina and stomach) to neutral and slightly alkaline (bloodstream and gut) (Davis 2003; Vylkova

CONTACT Sónia Silva soniasilva@deb.uminho.pt

(4) Supplemental data for this article is available online at https://doi.org/10.1080/08927014.2020.1793963.

(C) 2020 Informa UK Limited, trading as Taylor \& Francis Group 
et al. 2011). The environmental $\mathrm{pH}$ affects Candida cells, especially at their plasma membranes, including having effects on protein activity, proton gradients and nutrient availability (Davis 2003). Importantly, changes in the environmental $\mathrm{pH}$ can occur within some niches. For example, the vaginal tract has a normal pH of $\sim 4$ but this can increase to 5.5-7.5 during menstruation, pre-puberty or post-menopause (García-Closas et al. 1999) or in the presence of exogenous substances (Bouvet et al. 1997; Polatti et al. 2006). The vaginal tract is an interesting niche, because its acidity is a recognized barrier against most pathogens, but Candida species cause infection at its normal acidic pH (Linhares et al. 2011; Hickey et al. 2012). Previous studies have reported that an acidic $\mathrm{pH}$ has a significant impact on biofilm formation by Candida species (Kucharikova et al. 2011; Ferreira et al. 2016). However, the effect of specific vaginal acidity, which is mainly promoted by the production of lactic acid by the vaginal mucosa (L-lactate) and bacteria (L-lactate and D-lactate) (Boskey et al. 2001; Linhares et al. 2011), has not yet been investigated. Importantly, unlike other acids, lactic acid does not exert an inhibitory effect on Candida growth (Lourenço et al. 2019), contrasting with its effect on bacterial vaginal pathogens (O'Hanlon et al. 2011). As such, it is crucial to clarify the influence of vaginal acidic $\mathrm{pH}$ on Candida virulence factors, especially for the two most common species in the vaginal environment, C. albicans and C. glabrata. This study analysed relevant features of biofilms of $C$. albicans and $C$. glabrata developed under neutral and acidic conditions, the latter adjusted to $\mathrm{pH} 4$ with lactic acid (Llactate), as an approximation of the vaginal acidic environment. This knowledge will contribute to a better understanding of the modulation of $C$. albicans and C. glabrata biofilms by the vaginal acidity, providing relevant information for future studies of Candida vaginal virulence.

\section{Materials and methods}

\section{Strains and initial culture conditions}

In this study one reference strain and two vaginal isolates of C. albicans (SC5314, 557843 and 569322) and C. glabrata (ATCC 2001, 534784, 585626) were used. The isolates were supplied from the Biofilm Group collection (Centre of Biological Engineering, University of Minho, Braga, Portugal) and were isolated from patients at the Hospital of S. Marcos, Braga, Portugal. The identity of the isolates was confirmed using CHROMagar Candida (CHROMagar,
Paris, France) and PCR-based identification with specific primers (ITS1 and ITS4) (Williams et al. 1995).

Candida strains were grown on Sabouraud dextrose agar (SDA; Merck, Darmstadt, Germany) at $37^{\circ} \mathrm{C}$ for $48 \mathrm{~h}$. For each experiment, colonies collected from the SDA plates were used to inoculate $40 \mathrm{ml}$ of Sabouraud dextrose broth (SDB; Merck, Darmstadt, Germany), which was incubated at $37^{\circ} \mathrm{C}$ for $18 \mathrm{~h}$ under agitation $\left(120 \mathrm{rev} \mathrm{min}^{-1}\right)$. The cell suspension was centrifuged at $5,000 \mathrm{~g}$ for $10 \mathrm{~min}$ at $4{ }^{\circ} \mathrm{C}$ and the cells were washed twice with $10 \mathrm{ml}$ of sterile ultrapure water. The supernatant was discarded and the pellet was resuspended in Roswell Park Memorial Institute (RPMI-1640; Sigma-Aldrich, St Louis, Missouri) medium buffered with 3-(N-Morpholino) propanesulfonic acid (MOPS; Sigma-Aldrich, St Louis, Missouri). RPMI-1640 was used at $\mathrm{pH} 7$ or $\mathrm{pH} 4$ (adjusted with L-lactate; Merck, Darmstadt, Germany). For the planktonic and biofilm experiments the cell density was adjusted to $1 \times 10^{5}$ cells $\mathrm{ml}^{-1}$ using a Neubauer haemocytometer (Marienfeld, Lauda-Königshofen, Germany). The experiments described in the next sections were performed in triplicate (same pre-inoculum) and in three independent assays (pre-inocula independently prepared).

\section{Analysis of planktonic growth and filamentation}

For planktonic growth, cell suspensions of C. albicans and C. glabrata prepared in RPMI-1640 at $\mathrm{pH} 4$ and 7 were placed in $25 \mathrm{ml}$ Erlenmeyer flasks and incubated for $24 \mathrm{~h}$ at $37^{\circ} \mathrm{C}$ under agitation in an orbital shaker $\left(120 \mathrm{rev} \mathrm{min}^{-1}\right)$. Aliquots $(200 \mu \mathrm{l})$ were collected from the cell suspensions over $24 \mathrm{~h}$ and their optical density was measured, at $600 \mathrm{~nm}$, using a microtiter plate reader (Bio-Tek Synergy HT, Izasa, Winooski, Vermont). The $\mathrm{pH}$ was monitored throughout the experiment to ensure that the desired value was maintained.

Additionally, the filamentation of C. albicans strains was evaluated after cell growth for $24 \mathrm{~h}$. For this, an aliquot of cell suspension $(200 \mu \mathrm{l})$ was diluted in sterile water (1:100) and the filamentous forms were counted using an optical microscope and the results presented as a percentage of filamentous forms.

\section{Biofilm formation}

In order to develop C. albicans and C. glabrata biofilms, the cell suspensions prepared in RPMI-1640 at $\mathrm{pH} 4$ and 7 were placed in 96-well polystyrene 
microtiter plates (Orange Scientific, Braine-IAlleud, Belgium) $(200 \mu$ l per well), which were incubated for $24 \mathrm{~h}$ at $37^{\circ} \mathrm{C}$ under agitation $\left(120 \mathrm{rev} \min ^{-1}\right.$ ) (Silva et al. 2009). After incubation, the medium was removed and the biofilms were washed with $200 \mu \mathrm{l}$ of Phosphate Buffered Saline (PBS; $0.01 \mathrm{M}$ ) to remove non-adherent cells. The $\mathrm{pH}$ was monitored throughout the experiments to ensure that the desired value was maintained. The biofilms were analysed as described in the next sections.

\section{Quantification of biofilm biomass}

The total biomass of biofilms was quantified using the Crystal violet $(\mathrm{CV})$ staining methodology (Silva et al. 2009). For that, the biofilms developed were fixed with methanol $(200 \mu \mathrm{l}$ per well) for $15 \mathrm{~min}$ and then stained with CV $\left(1 \% \mathrm{v} v^{-1} ; 200 \mu\right.$ l per well) for $5 \mathrm{~min}$. The excess dye was removed by washing the biofilms twice with sterile water. Finally, $200 \mu \mathrm{l}$ of acetic acid $\left(33 \%, \mathrm{v} v^{-1}\right)$ were added to each well and the solutions were homogenized to release and dissolve the dye. The absorbance of the solutions was measured on a microtiter plate reader (Bio-Tek Synergy HT, Izasa, Winooski, Vermont) at $570 \mathrm{~nm}$ and the results presented as absorbance per unit area

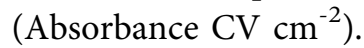

\section{Determination of biofilm cell cultivability}

The number of cultivable cells in the biofilms was estimated using the colony forming units (CFU) counting methodology (Silva et al. 2010). Briefly, the biofilms developed were scraped from the microtiter plate wells in the presence of $200 \mu \mathrm{l}$ of PBS and the suspensions were vigorously vortexed for $2 \mathrm{~min}$ to disaggregate the cells (Silva et al. 2010). Serial 10-fold dilutions were prepared of the biofilm suspensions in PBS, which were plated onto SDA plates $(10 \mu \mathrm{l})$ and incubated for $24 \mathrm{~h}$ at $37^{\circ} \mathrm{C}$. After incubation, the number of CFU on the SDA plates was counted and the results presented per unit area $\left(\log \mathrm{CFU} \mathrm{cm} \mathrm{cm}^{-2}\right)$.

\section{Biofilm thickness analysis}

A confocal laser scanning microscope (CLSM) was used to analyse the thickness of biofilms developed for $24 \mathrm{~h}$, as previously described, but using 24-well polystyrene microtiter plates (Orange Scientific, Braine-IAlleud, Belgium) (1 ml per well). The biofilms were stained with $1 \%\left(\mathrm{v} v^{-1}\right)$ Calcofluor white (Sigma-Aldrich, St Louis, Missouri) for $10 \mathrm{~min}$ at room temperature in the dark and then observed with a CLSM (Olympus BX61, Model FluoView 1000, Portugal). Excitation line 405 and emission filters BA 430-470 (blue channel) were used and images were acquired with the program FV10-ASW 4.2 (Olympus). The biofilm thickness was analysed in three areas of each image and the median thickness value was calculated for each replicate.

\section{Analysis of filamentous forms in biofilm cells}

The percentage of filamentous forms in the C. albicans biofilm cells, was determined from the biofilm suspensions, as previously described for planktonic cells. The filamentous forms of biofilm cells were also visualized with a CLSM, as described in the previous section.

\section{Biofilm matrix extraction and analysis}

In order to extract the biofilm matrix, C. albicans and C. glabrata biofilms were developed as described above, using 24 -well polystyrene microtiter plates, and then scraped from the wells, resuspended in ultrapure water and sonicated (Ultrasonic Processor, ColeParmer, Vernon Hills, Illinois) for $30 \mathrm{~s}$ at $30 \mathrm{~W}$ (Silva et al. 2009). The suspensions were vortexed for $2 \mathrm{~min}$ and centrifuged at 5,000 g for $5 \mathrm{~min}$. The pellets were dried at $37^{\circ} \mathrm{C}$ until a constant weight was obtained. The matrix-containing supernatants were filtered through a $0.2 \mu \mathrm{m}$ nitrocellulose filter and then the protein, total carbohydrate and (1,3)- $\beta$-D-glucan contents were estimated as described in the following sections.

\section{Protein quantification}

The protein content was measured using the BCA Kit (Bicinchoninic Acid, Sigma-Aldrich, St Louis, Missouri) and bovine serum albumin (BSA) as standard (Silva et al. 2009). Briefly, $0.2 \mathrm{ml}$ of BCA solution were added to $25 \mu \mathrm{l}$ of matrix sample and incubated for $30 \mathrm{~min}$ at $37^{\circ} \mathrm{C}$. Then, the absorbance was determined in a microplate reader at $562 \mathrm{~nm}$. The protein concentration was extrapolated from a calibration curve $(a b s=0.009 \times[$ protein $]+0.1685)$ performed with standard concentrations of BSA. The results were normalized with the dry weight of biofilm cells, previously determined, and presented as $\mathrm{mg}$ of protein per $\mathrm{g}$ of biofilm ( $\mathrm{mg} \mathrm{g}_{\text {biofilm }}{ }^{-1}$ ). 
Candida albicans

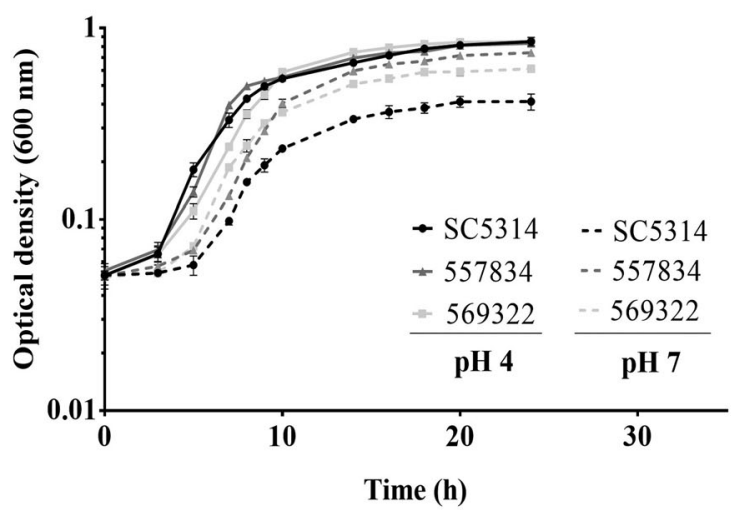

Candida glabrata

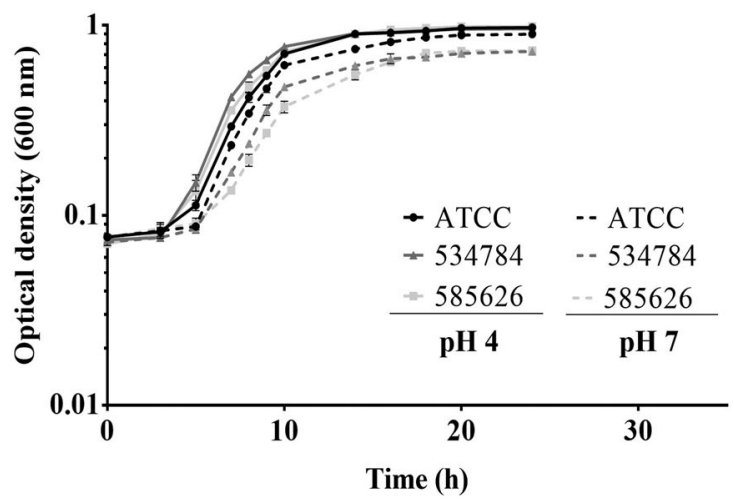

Figure 1. Planktonic growth of C. albicans and C. glabrata at pH 4 and pH 7. Growth curves (optical density) of C. albicans SC5314 (reference), 557834 and 569322 (vaginal isolates) and C. glabrata ATCC 2001 (reference), 537834 and 585626 (vaginal isolates), performed over $24 \mathrm{~h}$ at $\mathrm{pH} 4$ and 7 . Error bars represent SDs.

\section{Carbohydrate quantification}

The total carbohydrate content was estimated using the phenol-sulfuric method (DuBois et al. 1956) and glucose as standard. Briefly, $0.5 \mathrm{ml}$ of phenol $\left(50 \mathrm{~g} \mathrm{l}^{-1}\right)$ and $2.5 \mathrm{ml}$ of sulfuric acid (95-97\%) were added to $0.5 \mathrm{ml}$ of matrix sample. The solution was vortexed for $30 \mathrm{~s}$ and incubated for $15 \mathrm{~min}$ at room temperature. The absorbance was determined in a microtiter plate reader at $490 \mathrm{~nm}$. The concentration of carbohydrate was extrapolated from a calibration curve (Abs = $0.2955 \times$ [carbohydrate] +0.114 ) performed with standard glucose concentrations. The results were normalized with the dry weight of biofilm cells and presented as $\mathrm{mg}$ of carbohydrate per $\mathrm{g}$ of biofilm ( $\mathrm{mg} \mathrm{g}_{\text {biofilm }}{ }^{-1}$ ).

\section{(1,3)- $\beta$-D-glucan quantification}

The concentration of $(1,3)$ - $\beta$-D-glucan was determined using the Glucatell (1,3)- $\beta$-D-Glucan Detection Reagent kit (Associates of Cape Cod Inc., East Falmouth, Massachusetts). Briefly, $50 \mu \mathrm{l}$ of Glucatell reagent were added to $50 \mu \mathrm{l}$ of matrix sample and the solution was incubated at $37^{\circ} \mathrm{C}$ for $30 \mathrm{~min}$. The reaction was stopped by adding $50 \mu$ of sodium nitrite and sequentially $50 \mu \mathrm{l}$ of ammonium sulfamate and $50 \mu \mathrm{l}$ of $\mathrm{N}$-(1-Napthyl) ethylenediamine dihydrochloride. The optical density was read at $540 \mathrm{~nm}$ and the concentration of $(1,3)-\beta$-D-glucan was extrapolated from a calibration curve performed with standard glucan concentrations $($ Abs $=0.0106 \times$ [glucans] +0.0392$)$. The results were normalized with the dry weight of biofilm cells and presented as ng of $(1,3)$ - $\beta$-D-glucan per $\mathrm{g}$ of biofilm (ng $\mathrm{g}_{\text {biofilm }}{ }^{-1}$ ).

\section{Statistical analysis}

The results of biofilm biomass, cells cultivability, filamentation and matrix composition were analysed statistically using GraphPad Prism 6 software. The results obtained at $\mathrm{pH} 4$ were compared with those obtained at $\mathrm{pH} 7$ using the $t$ test analysis. All tests were performed with a confidence level of $95 \%$.

\section{Results}

\section{Planktonic growth under acidic and neutral conditions}

In order to analyse the influence of $\mathrm{pH}$ on the planktonic growth of $C$. albicans and C. glabrata strains, the optical density of free-floating cells growing in RPMI-1640 buffered to $\mathrm{pH} 4$ and 7 was monitored for $24 \mathrm{~h}$. The expected growth stages were obtained for all the C. albicans and C. glabrata strains under the conditions tested (Figure 1). The growth of $C$. glabrata strains was similar under both conditions, with the C. albicans strains having a slightly faster growth rate under acidic than neutral conditions. Additionally, the growth of the reference strain and the vaginal isolates was similar in both species under both conditions (Figure 1).

\section{Biofilm formation under acidic and neutral conditions}

In order to study the influence of $\mathrm{pH}$ on the formation of biofilms, biofilms were developed for $24 \mathrm{~h}$ in RPMI-1640 at $\mathrm{pH} 4$ and 7, and analysed in terms of 
A

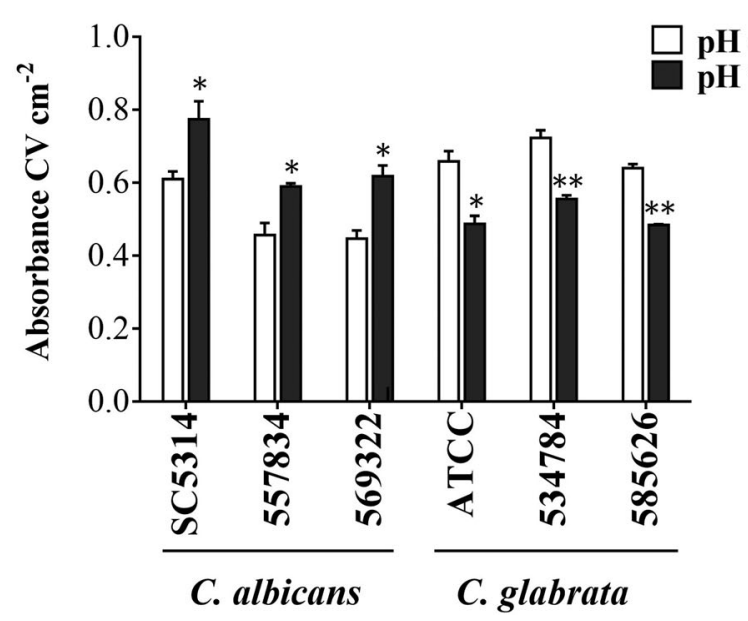

B

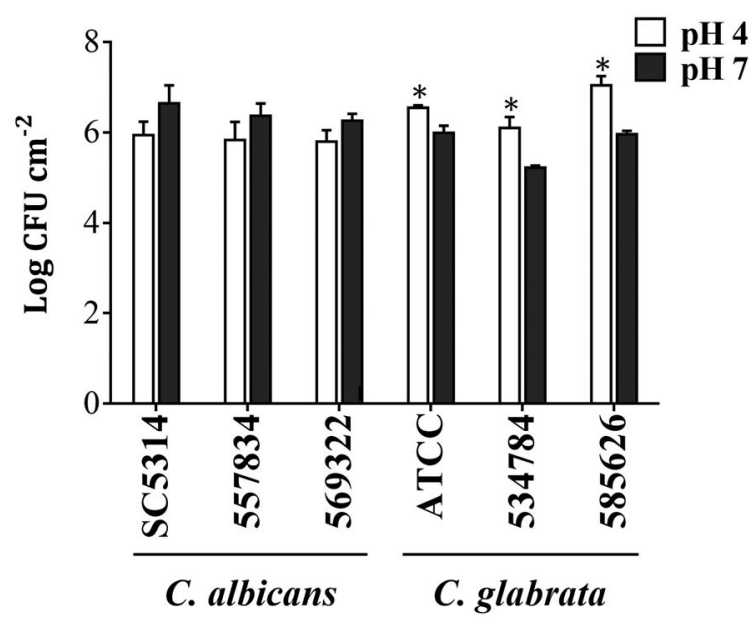

Figure 2. Biofilm formation by C. albicans and C. glabrata at pH 4 and pH 7. (A) Total biomass quantification (Absorbance CV $\mathrm{cm}^{-2}$ ) and (B) cultivable cell determination (Log CFU cm${ }^{-2}$ ) of C. albicans SC5314 (reference), 557834 and 569322 (vaginal isolates) and C. glabrata ATCC 2001 (reference), 537834 and 585626 (vaginal isolates) biofilms, developed over $24 \mathrm{~h}$ at pH 4 and pH 7. Error bars represent SDs; asterisks represent statistical differences between the results obtained at $\mathrm{pH} 4$ and $\mathrm{pH} 7$ (** $p$-value $\leq$ $0.01{ }^{*} p$-value $\left.\leq 0.05\right)$.

total biomass (Figure 2A) and the number of cultivable cells (Figure 2B). All strains of C. albicans and C. glabrata formed biofilms under both conditions, with $\mathrm{pH}$ having a different effect on each species (Figure 2). A statistically lower amount of biomass ( $p$-value $\leq 0.05$ ) was found in biofilms of $C$. albicans at $\mathrm{pH} 4$ than at $\mathrm{pH}$ 7 , with an average difference between the conditions of $20 \%$ (Figure 2A). Consistently, C. albicans biofilms developed at $\mathrm{pH} 4$ contained fewer cultivable cells than those formed at $\mathrm{pH} 7$, although the difference was not statistically significant ( $p$-value $>0.05$ ) (Figure $2 \mathrm{~B}$ ).

In contrast, a greater amount of biomass ( $p$-value $\leq 0.01)$ and a higher number of cultivable cells ( $p$ value $\leq 0.05$ ) were found in biofilms of $C$. glabrata at $\mathrm{pH} 4$ than at $\mathrm{pH}$ 7. The average difference between the conditions was $24 \%$ (Figure $2 \mathrm{~A}$ ) and 1 order of magnitude ( $\log \mathrm{CFU}\left(\mathrm{cm}^{-2}\right)$ (Figure 2B) for total biomass and cell cultivability, respectively.

C. albicans and C. glabrata biofilms were further analysed with a CLSM in order to determine their thickness. C. albicans biofilms formed at $\mathrm{pH} 4$ were thinner than biofilms formed at $\mathrm{pH} 7$ (Table 1 and Supplementary Figure S1), consistent with the previous analyses (Figure 2 ). In contrast, and also in accordance with the previous results (Figure 2), C. glabrata biofilms formed at $\mathrm{pH} 4$ were thicker $(p$-value $\leq 0.05)$ than biofilms formed at pH 7 (Table 1 and Supplementary Figure S2).

\section{Effect of $\mathrm{pH}$ on C. albicans filamentation}

C. albicans strains grown in the planktonic and biofilm lifestyles were analysed by optical microscopy in
Table 1. Effect of pH on the biofilm thickness of $C$. albicans and C. glabrata.

\begin{tabular}{llcc}
\hline & & \multicolumn{2}{c}{ Biofilm thickness $(\mu \mathrm{m})$} \\
\cline { 3 - 4 } Species & \multicolumn{1}{c}{ Strain } & $\mathrm{pH} \mathrm{4}$ & $\mathrm{pH} \mathrm{7}$ \\
\hline C. albicans & SC5314 & $15.5 \pm 1.2$ & $28.3 \pm 1.5^{* *}$ \\
& 557834 & $13.4 \pm 0.9$ & $16.1 \pm 1.7$ \\
C. glabrata & 569322 & $13.0 \pm 2.9$ & $20.0 \pm 3.1^{*}$ \\
& ATCC 2001 & $18.2 \pm 1.8$ & $12.3 \pm 2.1^{*}$ \\
& 534784 & $25.5 \pm 2.2$ & $15.6 \pm 2.4^{* *}$ \\
& 585626 & $21.2 \pm 2.5$ & $13.8 \pm 3.3^{*}$ \\
\hline
\end{tabular}

Thickness $(\mu \mathrm{m})$ of $C$. albicans and C. glabrata biofilms developed for $24 \mathrm{~h}$ at $\mathrm{pH} 4$ and $\mathrm{pH}$ 7. Asterisks represent a statistical difference between the results obtained at $\mathrm{pH} 4$ and $\mathrm{pH} 7(* * p$-value $\leq 0.01 ; * p$-value $\leq 0.05)$. The images of biofilms obtained by CLSM are available in Supplementary Figures S1 and S2.

order to evaluate the effect of $\mathrm{pH}$ on the development of filamentous forms (Figure 3). A higher percentage of filamentous forms was found at $\mathrm{pH} 7$ than at $\mathrm{pH}$ 4 , independent of the growth style (Figure $3 \mathrm{~A}$ ). The percentage of filamentous forms was statistically higher ( $p$-value $\leq 0.05)$ under neutral than under acidic conditions for C. albicans SC5314 and 585626. These two strains formed $\sim 50 \%$ and $10 \%$ more filaments at $\mathrm{pH} 7$ than at $\mathrm{pH} 4$, respectively (Figure $3 \mathrm{~A}$ ). C. albicans 557834 showed a poor ability to produce filaments but a higher percentage of filaments was also found at $\mathrm{pH} 7$ than at $\mathrm{pH} 4$.

The length of the filamentous forms formed by biofilm cells was evaluated by selecting CLSM images from a zone of the biofilm in which the cells with filaments were visible at high resolution (Figure 3B). More filaments with a longer length were found at $\mathrm{pH} 7$ than at $\mathrm{pH} 4$ for C. albicans SC5314 and 569322. In C. albicans 557834 filaments were not 


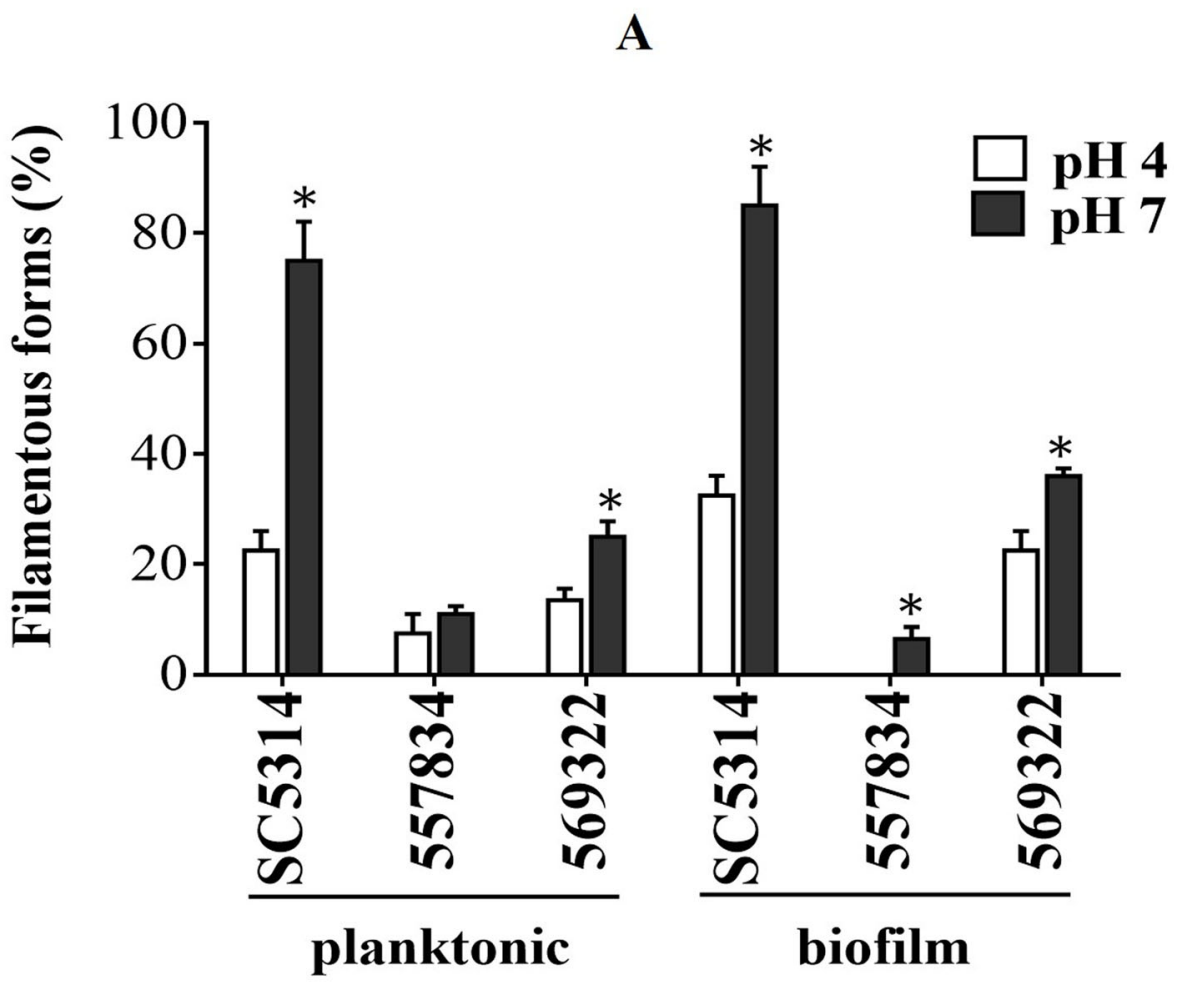

B
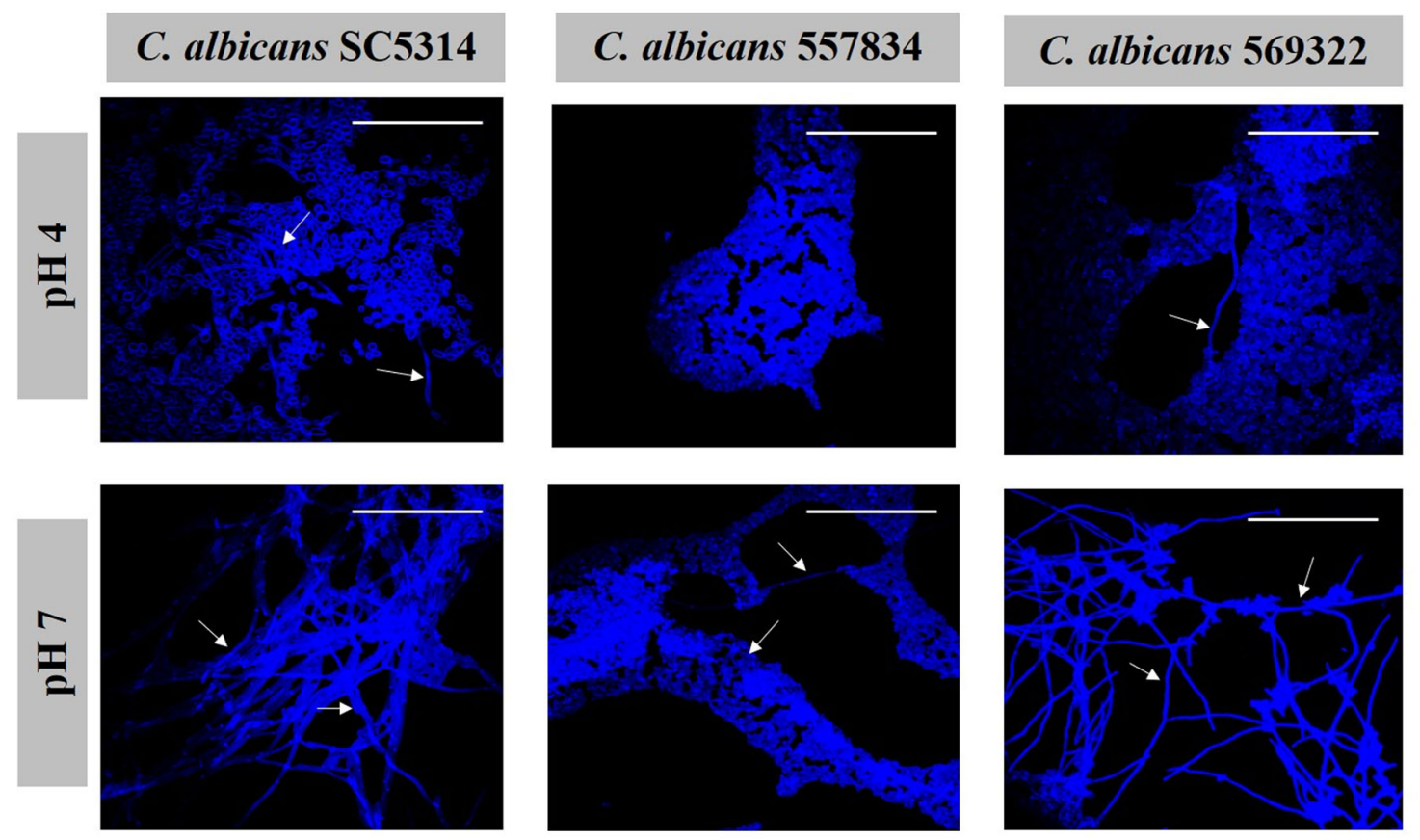

Figure 3. Effect of $\mathrm{pH}$ on filamentous form development in C. albicans. (A) Percentage of filamentous forms of $C$. albicans SC5314, 557834 and 569322 cells grown in planktonic and biofilm lifestyles for $24 \mathrm{~h}$ at $\mathrm{pH} 4$ and $\mathrm{pH}$ 7. Error bars represent SDs; asterisks represent statistical differences between the results obtained at $\mathrm{pH} 4$ and $\mathrm{pH} 7$ (* $p$-value $\leq 0.05$ ). (B) CLS images of $C$. albicans biofilm cells grown at $\mathrm{pH} 4$ and 7. Arrows point to filamentous forms. Original magnification $=60 \mathrm{x} ;$ bar $=100 \mu \mathrm{m}$. 
Table 2. Influence of $\mathrm{pH}$ on the biofilm matrix composition of C. albicans and C. glabrata.

\begin{tabular}{llllll}
\hline Species & Strain & pH & $\begin{array}{c}\text { Protein } \\
\left(\mathrm{mg} \mathrm{g}_{\text {biofilm }}{ }^{-1}\right)\end{array}$ & $\begin{array}{c}\text { Carbohydrate } \\
\left(\mathrm{mg} \mathrm{g}_{\text {biofilm }}{ }^{-1}\right)\end{array}$ & $\begin{array}{c}(1,3)-\beta-\mathrm{D}-\text { glucan } \\
(\mathrm{ng} \mathrm{g} \text { biofilm }\end{array}$ \\
\hline C. albicans & SC5314 & 4 & $42.92 \pm 5.11$ & $148.48 \pm 11.37$ & $47.47 \pm 1.43$ \\
& & 7 & $64.31 \pm 11.39$ & $578.20 \pm 10.26^{* * *}$ & $73.65 \pm 6.57^{*}$ \\
& 557834 & 4 & $56.39 \pm 7.27$ & $398.48 \pm 13.16$ & $50.40 \pm 2.94$ \\
& & 7 & $65.00 \pm 6.09$ & $889.20 \pm 12.79^{* * *}$ & $75.47 \pm 3.40^{*}$ \\
C. glabrata & 569322 & 4 & $50.69 \pm 7.07$ & $123.94 \pm 5.38$ & $54.00 \pm 2.84$ \\
& & 7 & $77.36 \pm 6.68$ & $839.93 \pm 7.25^{* * * *}$ & $78.34 \pm 5.70^{*}$ \\
& ATCC 2001 & 4 & $37.68 \pm 8.64$ & $104.23 \pm 13.4$ & $45.91 \pm 1.16$ \\
& & 7 & $73.89 \pm 4.52^{* *}$ & $511.42 \pm 6.58^{* * *}$ & $83.82 \pm 2.94^{* *}$ \\
& 534784 & 4 & $57.92 \pm 1.18$ & $99.83 \pm 11.96$ & $62.79 \pm 6.62$ \\
& & 7 & $59.74 \pm 6.1$ & $772.42 \pm 6.78^{* * *}$ & $89.75 \pm 2.28^{*}$ \\
& 585626 & 4 & $55.28 \pm 6.87$ & $296.39 \pm 5.18$ & $55.73 \pm 3.35$ \\
& & 7 & $29.31 \pm 7.46$ & $167.94 \pm 16.15^{* *}$ & $41.02 \pm 0.42^{*}$ \\
\hline
\end{tabular}

Amount of protein, carbohydrate and (1,3)- $\beta$ - D-glucan in the matrix of $C$. albicans and C. glabrata biofilms developed at pH 4 and pH 7. Asterisks represent a statistical difference between the results obtained at $\mathrm{pH} 4$ and $\mathrm{pH} 7$ (**** $p$-value $\leq 0.0001 ; * * * p$-value $\leq 0.001 ; * * p$-value $\leq 0.01 ; * p$-value $\leq 0.05)$.

observed in the biofilms formed at $\mathrm{pH} 4$ and those seen at $\mathrm{pH} 7$ were shorter than those seen with the other strains (Figure 3B and Supplementary Figure S1).

\section{Influence of pH on biofilm matrix composition}

The matrix of C. albicans and C. glabrata biofilms was analysed to evaluate the influence of $\mathrm{pH}$ on the amounts of the major components, namely protein and carbohydrate (total content and (1,3)- $\beta$-D-glucan) present. The results showed that the $\mathrm{pH}$ significantly affected the composition of the biofilm matrix in both species (Table 2).

In all C. albicans strains, a higher amount of protein and carbohydrate was found in the matrix of biofilms formed under neutral compared with acidic conditions (Table 2). In C. albicans 569322, the amount of total carbohydrate measured at $\mathrm{pH} 7$ was $\sim$ six times higher than that measured at $\mathrm{pH} 4$, and in the reference strain, it was almost four times higher than under neutral conditions (Table 2). Consistently, a statistically higher $(p$-value $\leq 0.05)$ amount of (1,3)- $\beta$-D-glucan was found in the matrix of C. albicans biofilms formed under neutral than under acidic conditions (Table 2). The content of this component found at $\mathrm{pH} 7$ was $\sim 1.5$ times than that found at $\mathrm{pH} 4$, in all strains. Additionally, a higher protein content was also found in the matrix of $C$. albicans biofilms formed under neutral conditions, but the difference in relation to the acidic environment was not statistically significant ( $p$-value $>0.05$ ).

In contrast with $C$. albicans, the influence of $\mathrm{pH}$ on the composition of the C. glabrata biofilm matrix was not similar for all strains. The amount of carbohydrate and protein found in the matrix of C. glabrata 585626 biofilms formed at $\mathrm{pH} 7$ was almost half of that found at $\mathrm{pH} 4$ (Table 2). In comparison, the amount of carbohydrate found in the matrix C. glabrata 534784 biofilms at $\mathrm{pH} 7$ was $\sim$ seven times higher than that found at $\mathrm{pH} 4$, and in the reference strain the amount was $\sim$ five times higher under neutral conditions (Table 2). Consistently, a statistically higher ( $p$-value $\leq 0.05)$ amount of $(1,3)-\beta$-D-glucan and a higher protein content were found in the matrix of the biofilms formed at neutral than in acidic conditions (Table 2).

\section{Discussion}

The ability of Candida species to adapt to the environmental $\mathrm{pH}$ of host niches is important for their success as commensals and as pathogens (Davis 2003). Importantly, the vaginal acidic $\mathrm{pH}$ is promoted by lactic acid, which has a particular non-inhibitory effect on Candida growth (Lourenço et al. 2019). As such, this study aimed to investigate the features of $C$. albicans and C. glabrata biofilms (reference strains and vaginal isolates) developed under a condition mimicking vaginal acidity ( $\mathrm{pH} \mathrm{4}$, with lactic acid), and compare them with those formed in a neutral environment. This study revealed a relevant and species-specific modulation of Candida biofilms by the vaginal acidity.

C. albicans developed biofilms with less biomass under acidic than under neutral conditions (Figure $2 \mathrm{~A}$ ), although the biofilm cell cultivability was not significantly affected (Figure 2B). Fewer and shorter filamentous forms were found in biofilms formed at $\mathrm{pH} 4$ than at $\mathrm{pH} 7$ (Figure 3 and Supplementary Figure S1), in line with the lower biomass found under acidic conditions (Figure 2A). Importantly, the reduced filamentation of $C$. albicans in an acidic $\mathrm{pH}$ has been suggested to facilitate the dispersion of biofilm cells displaying potentiated virulence traits, thus 
contributing to the establishment of new foci of infection (Uppuluri et al. 2010). This is especially relevant for women using intrauterine devices, to which Candida species can easily adhere and form biofilms, becoming a source of highly virulent pathogens (Chassot et al. 2008).

Besides reduced filamentation, C. albicans biofilms developed under acidic conditions produced lower amounts of matrix components, especially carbohydrates, than those formed at neutral $\mathrm{pH}$ (Table 2). To the authors' knowledge this is the first study regarding the influence of $\mathrm{pH}$ on the Candida biofilm matrix. A predominant role has been demonstrated for matrix carbohydrates in the resistance of C. albicans biofilms to antifungal agents (Nett et al. 2010; Dominguez et al. 2018). In accordance, lower resistance to caspofungin was reported for C. albicans biofilms formed under acidic than under neutral conditions (Kucharikova et al. 2011). Caspofungin exerts its activity by inhibiting $(1,3)$ - $\beta$-D-glucan synthases (Andriole 2000) and consistently, a lower content of $(1,3)-\beta$-D-glucan was found in the matrix of C. albicans biofilms formed under an acidic than under a neutral $\mathrm{pH}$ (Table 2).

In contrast to C. albicans, C. glabrata formed thicker biofilms (Table 1), with higher cell cultivability (Figure $2 \mathrm{~B}$ ), under acidic than under neutral conditions. The promotion of $C$. glabrata biofilm formation by the acidic conditions used in this study suggests that this species may exhibit high adaptability to the acidic vaginal environment. Strains of C. glabrata have commonly been isolated from women with recurrent vulvovaginal candidiasis (Grigoriou et al. 2006; Amouri et al. 2011). Recurrent episodes are suggested to result from the high ability of Candida species to adapt and form biofilms in the vaginal environment, making it difficult to eradicate this pathogen from the vaginal lumen (Sobel 2007; Harriott et al. 2010). Interestingly, proteomic analyses performed by Schmidt et. al (2008) suggested that $C$. glabrata perceives a low $\mathrm{pH}$ as less stressful than a higher $\mathrm{pH}$, what is consistent with the idea that this species is an opportunistic pathogen of humans that has evolved primarily in relatively acidic environmental niches such as root fruit (Schmidt et al. 2008).

Unlike C. albicans, the influence of $\mathrm{pH}$ on C. glabrata biofilm matrix, was not consistent among strains. In C. glabrata 585626 the production of a biofilm matrix was higher under acidic than under neutral conditions, but in the reference strain and C. glabrata 534784 the opposite result was found (Table 2). These results suggest that a higher production of biofilm matrix under neutral conditions may be a mechanism of protection in response to a more stressful environment for C. glabrata strains (Schmidt et al. 2008), but this mechanism must be dependent on the strain.

Importantly, the results bring new insights into the modulation of C. albicans and C. glabrata biofilms by the specific vaginal acidity (with lactic acid), This study contrasts with that of Kucharikova et al. (2011), who found lower biofilm formation at acidic ( $\mathrm{pH} 5.6$ and hydrochloric acid) compared with neutral conditions, in both species. Unlike other acids, lactic acid has been shown to exhibit no inhibitory effect on $C$. albicans and C. glabrata growth, even at high concentrations (Lourenço et al. 2019), thus in line with the results obtained in the current study (Figures 1 and 2). The tolerance of Candida species to lactic acid is attributed to their rapid ability to utilize it for their metabolism, which is suggested to favour Candida species by improving their metabolic versatility in niches often deprived of glucose such as the vaginal tract (Childers et al. 2016; Lourenço et al. 2019). This study suggests that Candida species exhibit a specific adaptation to the vaginal acidity, and thus, acidic experiments with acids other than lactic may not be suitable for extrapolation to the vaginal environment. Furthermore, this study shows relevant differences between the response of $C$. albicans and C. glabrata biofilms to the environmental $\mathrm{pH}$ that could have significance with respect to their response to drugs and host defences, hampering the management of Candida infections. Importantly, the results shown for C. albicans suggest that a higher concentration of drugs and/or longer treatment time may be necessary to effectively treat biofilm-related infections of this species in a neutral environment, such as the bloodstream, than in the acidic vaginal environment. Moreover, the vaginal environment may become temporarily or permanently neutral under certain conditions, owing to an impaired production of lactic acid (García-Closas et al. 1999; Polatti et al. 2006). Thus, vaginal $\mathrm{pH}$ seems to be a relevant factor to consider when applying a treatment for vulvovaginal candidiasis caused by $C$. albicans. Additionally, the findings suggest that inherent physiological differences between $C$ glabrata strains may lead to different biofilm responses to drugs under similar environmental $\mathrm{pH}$ conditions. Future studies, with higher numbers of isolates, will be crucial to investigate an explicit strain-dependency in C. glabrata and to definitely confirm the end-consequences indicated by this study.

The ability of Candida species to adapt to different environmental $\mathrm{pH}$ conditions is crucial for their 
survival at the mucosa and on medical devices. This study revealed, for the first time, the modulation of C. albicans and C. glabrata biofilms by vaginal acidity, leading to a better understanding of the adaptation and response of these species to the vaginal environment. Overall, this study provides a strong foundation for down-stream molecular work on Candida vaginal biofilms, showing that it is crucial to investigate species-specific virulence determinants for the vaginal environment in order to reveal new targets for the development of more efficient treatments for vulvovaginal candidiasis.

\section{Disclosure statement}

No potential conflict of interests was reported by the author(s).

\section{Funding}

This work was supported by the Portuguese Foundation for Science and Technology (FCT)] under the scope of the strategic funding of the [UID/BIO/04469/2019] unit and BioTecNorte operation [NORTE-01- 0145-FEDER-000004] funded by the European Regional Development Fund under the scope of Norte2020 - Programa Operacional Regional do Norte. This work was also supported by a [FCT] PhD grant [SFRH/BD/111645/2015].

\section{ORCID}

Bruna Gonçalves (D) http://orcid.org/0000-0003-4308-7567 Mariana Henriques (D) http://orcid.org/0000-00030317-4877

\section{References}

Alberto Cortés J, Fernanda Corrales I. 2019. Invasive candidiasis: epidemiology and risk factors. In: Fungal Infection. London (UK): IntechOpen.

Amouri I, Sellami H, Borji N, Abbes S, Sellami A, Cheikhrouhou F, Maazoun L, Khaled S, Khrouf S, Boujelben Y, et al. 2011. Epidemiological survey of vulvovaginal candidosis in Sfax, Tunisia. Mycoses. 54: e499-e505. doi:10.1111/j.1439-0507.2010.01965.x

Andriole VT. 2000. Current and future antifungal therapy: new targets for antifungal therapy. Int $\mathrm{J}$ Antimicrob Agents. 16:317-321. doi:10.1016/s0924-8579(00)00258-2

Bennett JE, Izumikawa K, Marr KA. 2004. Mechanism of increased fluconazole resistance in Candida glabrata during prophylaxis. Antimicrob Agents Chemother. 48: 1773-1777. doi:10.1128/aac.48.5.1773-1777.2004

Boskey ER, Cone RA, Whaley KJ, Moench TR. 2001. Origins of vaginal acidity: high $\mathrm{D} / \mathrm{L}$ lactate ratio is consistent with bacteria being the primary source. Hum Reprod. 16:1809-1813. doi:10.1093/humrep/16.9.1809
Bouvet J-P, Grésenguet G, Bélec L. 1997. Vaginal pH neutralization by semen as a cofactor of HIV transmission. Clin Microbiol Infect. 3:19-23. doi:10.1111/j.1469-0691. 1997.tb00246.x

Bouza E, Guinea J, Guembe M. 2014. The role of antifungals against Candida biofilm in catheter-related candidemia. Antibiotics (Basel). 4:1-17. doi:10.3390/ antibiotics 4010001

Chassot F, Negri MFN, Svidzinski AE, Donatti L, Peralta RM, Svidzinski TIE, Consolaro M. 2008. Can intrauterine contraceptive devices be a Candida albicans reservoir? Contraception. 77:355-359. doi:10.1016/j.contraception. 2008.01.007

Childers DS, Raziunaite I, Mol Avelar G, Mackie J, Budge S, Stead D, Gow NAR, Lenardon MD, Ballou ER, MacCallum DM, et al. 2016. The rewiring of ubiquitination targets in a pathogenic yeast promotes metabolic flexibility, host colonization and virulence. PLoS Pathog. 12:e1005566. doi:10.1371/journal.ppat.1005566

Davis D. 2003. Adaptation to environmental $\mathrm{pH}$ in Candida albicans and its relation to pathogenesis. Curr Genet. 44:1-7. doi:10.1007/s00294-003-0415-2

Dominguez E, Zarnowski R, Sanchez H, Covelli AS, Westler WM, Azadi P, Nett J, Mitchell AP, Andes DR. 2018. Conservation and divergence in the Candida species biofilm matrix mannan-glucan complex structure, function, and genetic control. MBio. 9:e00451. doi:10. 1128/mBio.00451-18

Donlan RM, Costerton JW. 2002. Biofilms: survival mechanisms of clinically relevant microorganisms. Clin Microbiol Rev. 15:167-193. doi:10.1128/cmr.15.2.167-193. 2002

DuBois M, Gilles KA, Hamilton JK, Rebers PA, Smith F. 1956. Colorimetric method for determination of sugars and related substances. Anal Chem. 28:350-356. doi:10. 1021/ac60111a017

Ferreira C, Gonçalves B, Vilas Boas D, Oliveira H, Henriques M, Azeredo J, Silva S. 2016. Candida tropicalis biofilm and human epithelium invasion is highly influenced by environmental pH. Pathog Dis. 74:ftw101. doi: 10.1093/femspd/ftw101

García-Closas M, Herrero R, Bratti C, Hildesheim A, Sherman ME, Morera LA, Schiffman M. 1999. Epidemiologic determinants of vaginal pH. Am J Obstet Gynecol. 180:1060-1066. doi:10.1016/s00029378(99)70595-8

Gonçalves B, Ferreira C, Alves CT, Henriques M, Azeredo J, Silva S. 2016. Vulvovaginal candidiasis: epidemiology, microbiology and risk factors. Crit Rev Microbiol. 42: 905-927. doi:10.3109/1040841X.2015.1091805

Grigoriou O, Baka S, Makrakis E, Hassiakos D, Kapparos G, Kouskouni E. 2006. Prevalence of clinical vaginal candidiasis in a university hospital and possible risk factors. Eur J Obstet Gynecol Reprod Biol. 126:121-125.

Gulati M, Nobile CJ. 2016. Candida albicans biofilms: development, regulation, and molecular mechanisms. Microbes Infect. 18:310-321. doi:10.1016/j.micinf.2016.01. 002

Harriott MM, Lilly EA, Rodriguez TE, Fidel PL, Noverr MC. 2010. Candida albicans forms biofilms on the vaginal mucosa. Microbiology . 156:3635-3644. doi:10.1099/ mic.0.039354-0 
Hickey RJ, Zhou X, Pierson JD, Ravel J, Forney LJ. 2012. Understanding vaginal microbiome complexity from an ecological perspective. Transl Res. 160:267-282. doi:10. 1016/j.trsl.2012.02.008

Kucharikova S, Tournu H, Lagrou K, Van Dijck P, Bujdakova H. 2011. Detailed comparison of Candida albicans and Candida glabrata biofilms under different conditions and their susceptibility to caspofungin and anidulafungin. J Med Microbiol. 60:1261-1269. doi:10. 1099/jmm.0.032037-0

Linhares IM, Summers PR, Larsen B, Giraldo PC, Witkin SS. 2011. Contemporary perspectives on vaginal $\mathrm{pH}$ and lactobacilli. Am J Obstet Gynecol. 204:120.e1-120.e5. doi: 10.1016/j.ajog.2010.07.010

Lourenço A, Pedro NA, Salazar SB, Mira NP. 2019. Effect of acetic acid and lactic acid at low $\mathrm{pH}$ in growth and azole resistance of Candida albicans and Candida glabrata. Front Microbiol. 9:1-11.

Nagashima M, Yamagishi Y, Mikamo H. 2016. Antifungal susceptibilities of Candida species isolated from the patients with vaginal candidiasis. J Infect Chemother. 22: 124-126. doi:10.1016/j.jiac.2015.08.008

Nett JE, Crawford K, Marchillo K, Andes DR. 2010. Role of Fks1p and matrix glucan in Candida albicans biofilm resistance to an echinocandin, pyrimidine, and polyene. Antimicrob Agents Chemother. 54:3505-3508. doi:10. 1128/AAC.00227-10

Nobile CJ, Fox EP, Nett JE, Sorrells TR, Mitrovich QM, Hernday AD, Tuch BB, Andes DR, Johnson AD. 2012. A recently evolved transcriptional network controls biofilm development in Candida albicans. Cell. 148:126-138. doi: 10.1016/j.cell.2011.10.048

O'Hanlon DE, Moench TR, Cone RA. 2011. In vaginal fluid, bacteria associated with bacterial vaginosis can be suppressed with lactic acid but not hydrogen peroxide. BMC Infect Dis. 11:200. doi:10.1186/1471-2334-11-200

Pappas PG, Kauffman CA, Andes DR, Clancy CJ, Marr KA, Ostrosky-Zeichner L, Reboli AC, Schuster MG, Vazquez JA, Walsh TJ, et al. 2016. Clinical practice guideline for the management of candidiasis: 2016 update by the
Infectious Diseases Society of America. Clin Infect Dis. 62:e1-e50. doi:10.1093/cid/civ1194

Polatti F, Rampino M, Magnani P, Mascarucci P. 2006. Vaginal $\mathrm{pH}$-lowering effect of locally applied vitamin $\mathrm{C}$ in subjects with high vaginal $\mathrm{pH}$. Gynecol Endocrinol. 22:230-234. doi:10.1080/09513590600647441

Schmidt P, Walker J, Selway L, Stead D, Yin Z, Enjalbert B, Weig M, Brown A. 2008. Proteomic analysis of the $\mathrm{pH}$ response in the fungal pathogen Candida glabrata. Proteomics. 8:534-544. doi:10.1002/pmic.200700845

Seneviratne CJ, Silva WJ, Jin LJ, Samaranayake YH, Samaranayake LP. 2009. Architectural analysis, viability assessment and growth kinetics of Candida albicans and Candida glabrata biofilms. Arch Oral Biol. 54:1052-1060. doi:10.1016/j.archoralbio.2009.08.002

Silva S, Henriques M, Martins A, Oliveira R, Williams D, Azeredo J. 2009. Biofilms of non-Candida albicans Candida species: quantification, structure and matrix composition. Med Mycol. 47:681-689. doi:10.3109/ 13693780802549594

Silva S, Henriques M, Oliveira R, Williams D, Azeredo J. 2010. In vitro biofilm activity of non-Candida albicans Candida species. Curr Microbiol. 61:534-540. doi:10. 1007/s00284-010-9649-7

Sobel JD. 2007. Vulvovaginal candidosis. Lancet. 369: 1961-1971. doi:10.1016/S0140-6736(07)60917-9

Uppuluri P, Chaturvedi AK, Srinivasan A, Banerjee M, Ramasubramaniam AK, Köhler JR, Kadosh D, LopezRibot JL. 2010. Dispersion as an important step in the Candida albicans biofilm developmental cycle. PLoS Pathog. 6:e1000828. doi:10.1371/journal.ppat.1000828

Vylkova S, Carman AJ, Danhof HA, Collette JR, Zhou H, Lorenz MC. 2011. The fungal pathogen Candida albicans autoinduces hyphal morphogenesis by raising extracellular pH.Taylor JW, editor. MBio. 2:e00055. doi:10.1128/ mBio.00055-11

Williams DW, Wilson MJ, Lewis MAO, Potts A. 1995. Identification of Candida species by PCR and restriction fragment length polymorphism analysis of intergenic spacer regions of ribosomal DNA. J Clin Microbiol. 33: 2476-2479. doi:10.1128/JCM.33.9.2476-2479.1995 